JOURNAL

of Health Inequalities

\title{
Differences in energy and selected macronutrients intake with diet between men and women from urban and rural areas of the Lower Silesia in Poland: the Polish arm of the Prospective Urban Rural Epidemiological (PURE) study
}

\author{
Dorota Różańska1, Bożena Regulska-llow', Rafał llow², Katarzyna Zatońska3 ${ }^{3}$, Maria Wołyniec³,

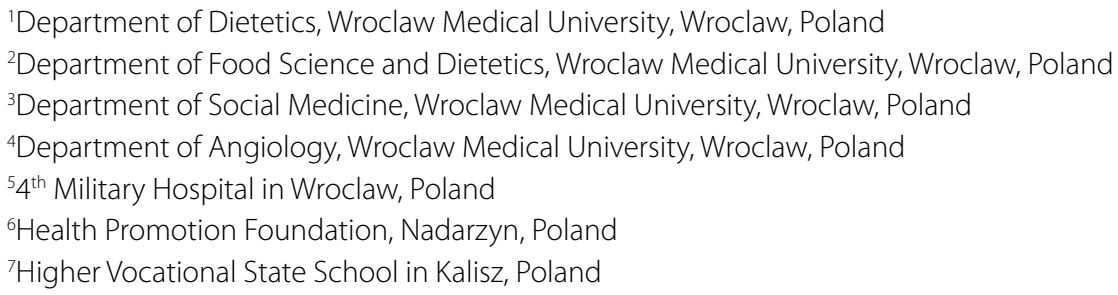
Anna Mandecka' ${ }^{1}$ Klaudia Konikowska' ${ }^{1}$ Agnieszka Salomon ${ }^{1}$, Alicja Basiak ${ }^{3}$, Andrzej Szuba ${ }^{4,5}$, Witold A. Zatoński ${ }^{6,7}$

\begin{abstract}
Introduction: Adherence to dietary recommendations is an important approach for primary prevention of non-communicable diseases. The aim of the study was to compare energy and selected macronutrients intake with diet between men and women from urban and rural areas who participated in the Polish arm of the Prospective Urban Rural Epidemiological (PURE) study, and to identify the proportion of individuals who did not meet dietary recommendations.

Material and methods: The study participants consisted of 1272 women and 753 men, aged 35-70 years from urban $(n=1200)$ and rural $(n=825)$ areas of Lower Silesian Voivodeship. Participants' habitual food intake was recorded using country-specific food frequency questionnaire (FFQ).

Results: Estimated daily energy intake was higher for men than women ( $2121 \mathrm{vs.} 2074 \mathrm{kcal}, p<0.05)$. Percentage energy provided by carbohydrates was $48 \%$, by fats was $32 \%$, and by protein was $15 \%$. The average energy intake from saturated fatty acids (SFA) was $12.4 \%$, from monounsaturated $10.9 \%$, while from polyunsaturated fatty acids (PUFA) $5.0 \%$, and the $\mathrm{P} / \mathrm{S}$ ratio was 0.44 . In the diets of $75 \%$ participants, the percentage energy provided by SFA was above $10 \%$. About $1 / 3$ of participants did not meet the recommended amount of fiber. The urban participants consumed less energy, fat and protein, but more carbohydrates than their rural counterpart. Conclusions: The diets that were closer to recommendations were observed among women and people residing urban areas compared to men and people residing rural areas. The studied diets were characterised by excessive percentage of energy from SFA and too low from PUFA.
\end{abstract}

KEY WORDS: diet, nutrients, fatty acids, Food Frequency Questionnaire, PURE study, FFQ.

\section{KEY FINDINGS}

The diets of women and people residing urban areas compared to men and people residing rural areas were closer to dietary recommendations. The excessive percentage of energy from saturated fatty acids and too low from polyunsaturated fatty acids was observed in the studied diets. Almost $40 \%$ of the study group consumed too much of cholesterol, while about one-third did not consume enough amounts of dietary fiber. The dietary faults observed in the study may increase the risk of non-communicable diseases in this population. 
ADDRESS FOR CORRESPONDENCE: Bożena Regulska-llow, Department of Dietetics, Wroclaw Medical University, 34 Parkowa Street, 51-616 Wroclaw, Poland, e-mail: bozena.regulska-ilow@umed.wroc.pl

\section{INTRODUCTION}

The effect of diet on the risk of cardiovascular disease (CVD) and CVD mortality have been extensively studied. Previous studies have shown decreased risk of CVD by higher PUFA and MUFA consumption, and elevated risk by increase intake of trans fat. The synergistic effect of all diets components determines the final impact on metabolic processes and monitoring the intake of nutrients, in comparison with recommendations, is widely used for assessing diet quality [1-3].

Large epidemiological and randomised control trails have shown the impact of healthy eating on prevalence and incidence of chronic diseases [4-6]. Adherence to dietary recommendation is the basis for prevention of non-communicable diseases such as obesity, diabetes type 2, and cardiovascular diseases [7-10].

The objectives of the present study were to compare energy and selected macronutrients intake with diet between men and women from urban and rural areas of the Lower Silesia who participated in the Polish arm of the Prospective Urban Rural Epidemiological (PURE) study. Also, to identify the proportion of individuals who did not meet dietary recommendations.

\section{MATERIAL AND METHODS}

This cross-sectional study includes participants from urban and rural areas of Lower Silesian Voivodeship in Poland, who were enrolled in the PURE study. The PURE study is a prospective cohort study of 158,092 men and women from 20 low, middle, and high income countries. The design and main findings of PURE study have been published previously $[11,12]$.

In the Polish arm of PURE study, 2025 individuals were enrolled. There were 1200 inhabitants of urban area (Wroclaw) and 825 inhabitants of rural areas (surrounded villages). The study was conducted between 2007 and 2009.

Nutritional data were collected using a food frequency questionnaire (FFQ), which was developed and validated for the population of the Polish arm of the PURE study [13]. The FFQ included 154 food items divided into following groups: milk and dairy products (20 items), fruits (13 items), vegetables (33 items), meat, eggs, etc. (23 items), breads and cereals ( 9 items), mixed dishes ( 21 items), beverages (17 items), and snacks (18 items). The questionnaire included typical products and dishes consumed in Poland. Participants were asked how often, on average, during the past year, they consumed each foods and drinks. There were 9 categories of frequency to choose: "never, less than once a month", "1-3 times a month", "once a week", "2-4 times a week", "5-6 times a week", "once a day", "2-3 times a day", " $4-5$ times a day", and "more than 6 times a day". All food items were described in portion sizes commonly consumed, e.g. 1 glass of milk, 1 teaspoon of margarine, 1 medium size apple, or 1 slice of bread. The average weight of food portions was determined during the FFQ validation, based on the reported portion size collected by $24 \mathrm{~h}$ dietary recalls. To compute the daily nutrient intake, the reported frequency of consumption for each food item was multiplied by the portion size, and then the total food intake was converted into nutrient intake. Based on the US Department and Agricultural [14] and Poland's Food Composition Tables [15], a special nutrient food database, which includes food and mixed dishes commonly eaten in Poland, was created [16]. Daily intake of foods and nutrients was computed at the Population Health Research Institute (PHRI) at McMaster University, Hamilton, Canada.

According to the Nutrition Recommendations for Polish Population, the percentage of energy from protein in diet should be between 10-15\% (Nutrition Recommendations for Polish Population, 2008), from fats 20-35\% (European Food Safety Authority - EFSA, 2010), and from carbohydrates $50-70 \%$ [17]. Therefore, to calculate the requirements (expressed in $\mathrm{g} /$ day) for these compounds, the percentage of energy from macronutrients in this study was assumed as follows: $12 \%$ from protein, $30 \%$ from fats, and $58 \%$ from carbohydrate. Considering that the percentage of total energy from fats was assumed as $30 \%$, the recommendation for saturated fatty acids (SFA), monounsaturated fatty acids (MUFA), and polyunsaturated fatty acids (PUFA), in this study were assumed as $8 \%, 15 \%$, and $7 \%$ of total energy, respectively. The recommended intake of macronutrients in $\mathrm{g} /$ day was evaluated based on the recommended daily energy intake. The recommended daily energy intake was computed for each person individually, according to gender, age, proper body weight, and physical activity level (assessed on the bases of the International Physical Activity Questionnaires - IPAQ). The recommended dietary fiber intake was set at $25 \mathrm{~g} /$ day, while the acceptable level of cholesterol intake was below $300 \mathrm{mg} /$ day.

To compare energy and nutrients intake with recommendations, two parameters were used such as: fulfillment of recommendations (mean \pm SD) and percentage of daily food rations (DFRs), which contained nutrients in amounts incompatible with recommendations.

\section{STATISTICAL ANALYSIS}

Means, SD, and median were calculated to summarise continuous variables. We compared energy and nutrients intake between sex and a place of residence (urban/rural). Differences in energy and nutrients 


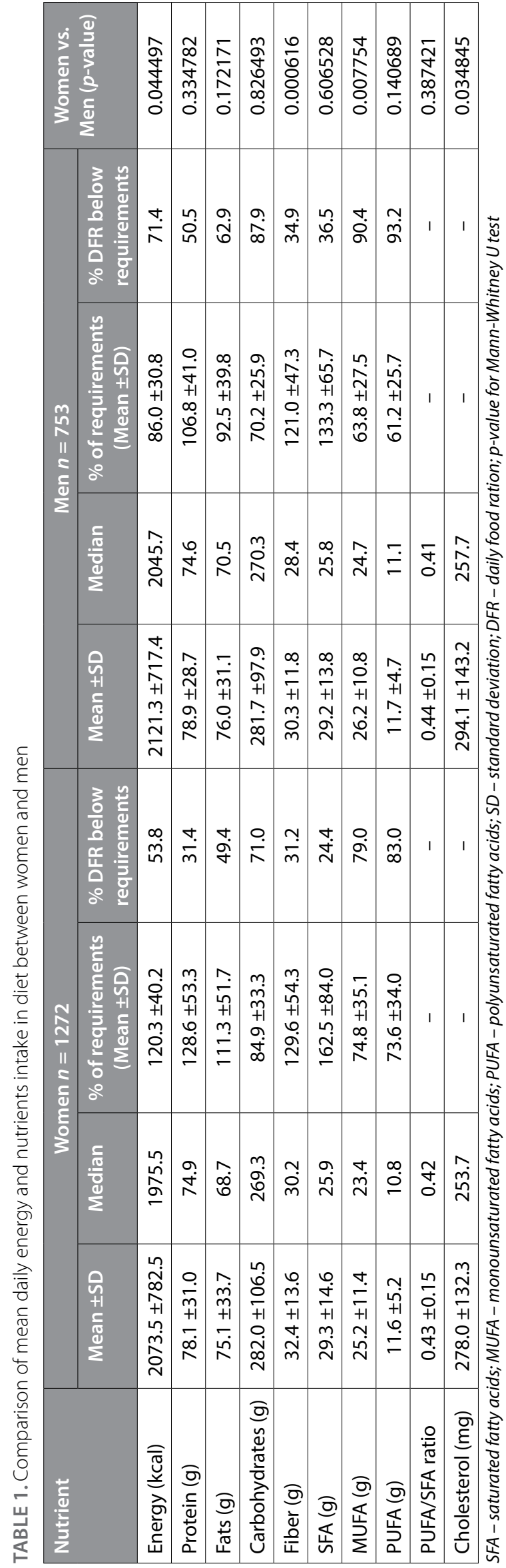

intake between groups were compared using non-parametric Mann-Whitney $U$ test or Kruskal-Wallis test. For all analysis, a $p$-value of less than 0.05 was considered to be statistically significant. Statistical analysis was performed using software STATISTICA, version 10.0 PL StatSoft Inc., USA.

\section{RESULTS}

Table 1 presents means ( \pm SD) daily intake of energy, macro and micro-nutrients by sex, and comparison of intakes with dietary recommendations. Men had slightly higher energy intake than women (2121.3 vs. 2073.5 $\mathrm{kcal} / \mathrm{day}, p=0.0445)$, but there were not statistically significant differences between protein, carbohydrates, and fats intake. Based on Dietary Reference Intakes (DRI), $79 \%$ of women and $90 \%$ of men had inadequate MUFA intake, and $83 \%$ and $93 \%$, respectively, had inadequate PUFA intake. The abnormalities observed in energetic structure of the diets were mainly caused by low percent of energy from MUFA and PUFA, while high intake of SFA, what presents Table 2.

Figure 1 shows percentage of the study group whose DFRs were incompatible with the recommendations, according to fatty acids, P/S ration, and cholesterol. Although the mean daily intake of cholesterol in both groups was below $300 \mathrm{mg}, 37 \%$ of women and $41 \%$ of men reported higher cholesterol intake than dietary recommendation. The diets of about $75 \%$ of the study group contained more than $10 \%$ of energy from SFA. Because of the improper proportions between PUFA and SFA, the $\mathrm{P} / \mathrm{S}$ ratio was very low and amounted to 0.44 . Only about $5 \%$ of the study group had $\mathrm{P} / \mathrm{S}$ ratio higher or equal to 0.70 . The percentage of energy from MUFA was lower than $10 \%$ in the diets of about one-third of the study population. Similarly, the mean dietary fiber content in DFRs was satisfactory but about $1 / 3$ of the study population consumed less than $25 \mathrm{~g}$ of this compound per day.

Lower energy and macronutrients were consumed in urban than rural areas, except dietary fiber, the intake of which was similar between urban and rural inhabitants (Table 3). The diets of women from urban area compared to rural area were characterised by higher percentage of energy form proteins and carbohydrates, and lower percentage of energy from fats. Among men, such differences were observed only for carbohydrates and fats. In the diets of urban inhabitants compared to the diets of rural inhabitants, both men and women, lower percentage of energy from SFA, MUFA, and PUFA was observed. Urban participants reported higher alcohol intake.

\section{DISCUSSION}

The paper presents the nutritional results obtained in the Polish arm of the PURE study that includes rural and urban inhabitants. The intake of energy, macronutrients, dietary fiber, and cholesterol in the study population were also compared dependent on sex and place of resi- 
TABLE 2. Comparison of energetic structure of the diets between women and men

\begin{tabular}{|l|c|c|c|c|c|}
\hline \multirow{2}{*}{ Nutrient } & \multicolumn{2}{|c|}{ Women $n=1272$} & \multicolumn{2}{c|}{ Men $n=753$} & $\begin{array}{c}\text { Women vs. Men } \\
(p \text {-value) }\end{array}$ \\
\cline { 2 - 5 } & Mean \pm SD & Median & Mean \pm SD & Median & 0.015913 \\
\hline Protein (\%E) & $15.1 \pm 2.1$ & 15.0 & $14.9 \pm 2.1$ & 14.8 & 0.160591 \\
\hline Fats (\%E) & $32.2 \pm 5.6$ & 32.0 & $31.9 \pm 5.8$ & 31.5 & 0.003660 \\
\hline Carbohydrates (\%E) & $48.4 \pm 5.8$ & 48.3 & $47.6 \pm 6.0$ & 47.8 & 0.039918 \\
\hline SFA (\%E) & $12.5 \pm 3.5$ & 11.9 & $12.2 \pm 3.5$ & 11.7 & 0.044907 \\
\hline MUFA (\%E) & $10.8 \pm 2.1$ & 10.8 & $11.0 \pm 2.1$ & 11.1 & 0.812311 \\
\hline PUFA (\%E) & $5.0 \pm 1.1$ & 4.9 & $5.0 \pm 1.0$ & 5.0 & $<0.0001$ \\
\hline Alcohol (\%E) & $0.6 \pm 1.1$ & 0.2 & $1.6 \pm 2.8$ & 1.0 & $<$ \\
\hline
\end{tabular}

$\% E$ - percentage of energy; SFA - saturated fatty acids; MUFA - monounsaturated fatty acids; PUFA - polyunsaturated fatty acids; SD - standard deviation; $p$-value for Mann-Whitney U test

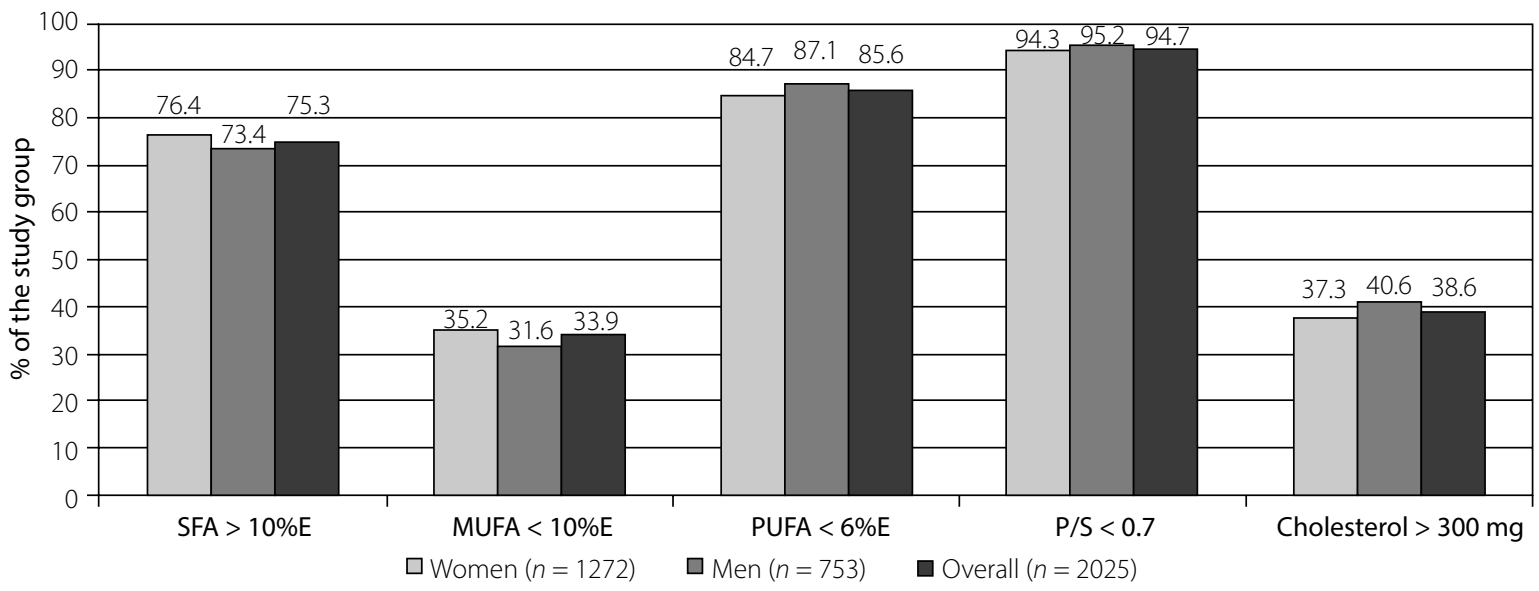

$\%$ - percentage of energy; SFA - saturated fatty acids; MUFA - monounsaturated fatty acids; PUFA - polyunsaturated fatty acids; P/S - PUFA SFA ratio

FIG. 1. Percentage of the study group whose daily food rations were incompatible with the recommendations

dence. Our findings showed that the assessed diets were not properly balanced. An average total fat content in the DFRs could be considered as acceptable, if not the incorrect contribution of selected groups of fatty acids. The ratio of polyunsaturated to saturated fatty acids indicates a potentially atherogenic properties of the diets. Moreover, the cholesterol content in the diets of about $39 \%$ of the study group exceeded the allowed $300 \mathrm{mg}$ /day. Although the percentage of energy from carbohydrates in the DFRs of the study population was low and did not exceed $50 \%$, the average content of dietary fiber was consistent with the requirements. The diets that were the least compatible with the recommendations were found in the studied men and people residing rural areas.

Mean daily energy intake of men was significantly higher than women, however, the difference was not as large as observed in other studies conducted in Poland $[18,19]$. Women from the Lower Silesian Voivodeship from WOBASZ (the National Multicenter Health Survey) study consumed $1641 \mathrm{kcal} / \mathrm{day}$ and women aged 50 year old from Wroclaw $1681 \mathrm{kcal} /$ day, whereas men consumed $2569 \mathrm{kcal} /$ day and $2329 \mathrm{kcal} /$ day, respectively
$[18,19]$. Lower daily energy intake in presented study, both in women and men $(1321 \mathrm{kcal}$ and $1461 \mathrm{kcal}$, respectively) was observed in PONS study (Polish-Norwegian Study) [20]. Excess of the recommended value of energy was observed, especially among women, as about $46 \%$ of them consumed to much calories with diet. In the group of men, this percentage was lower and accounted to almost $29 \%$. The balance between daily energy intake and energy expenditure is one of the most important factor, permitting to maintain the proper body weight. It is strongly worth to notice that among this population, there was about $68 \%$ of women and $79 \%$ of men with BMI greater or equal to $25 \mathrm{~kg} / \mathrm{m}^{2}$ (data not published).

The diets of the study population were not well balanced, what was characterised by too low intake of carbohydrates and improper proportion between fatty acids. Insufficient intake of carbohydrates was observed also in other studies, however, the average dietary fiber intake, in contrast to the previous studies, was adequate $[19,20]$. It may suggest that the intake of fruits and vegetables in this population was satisfactory but failed in the sufficient number of portions of cereals products. It is 


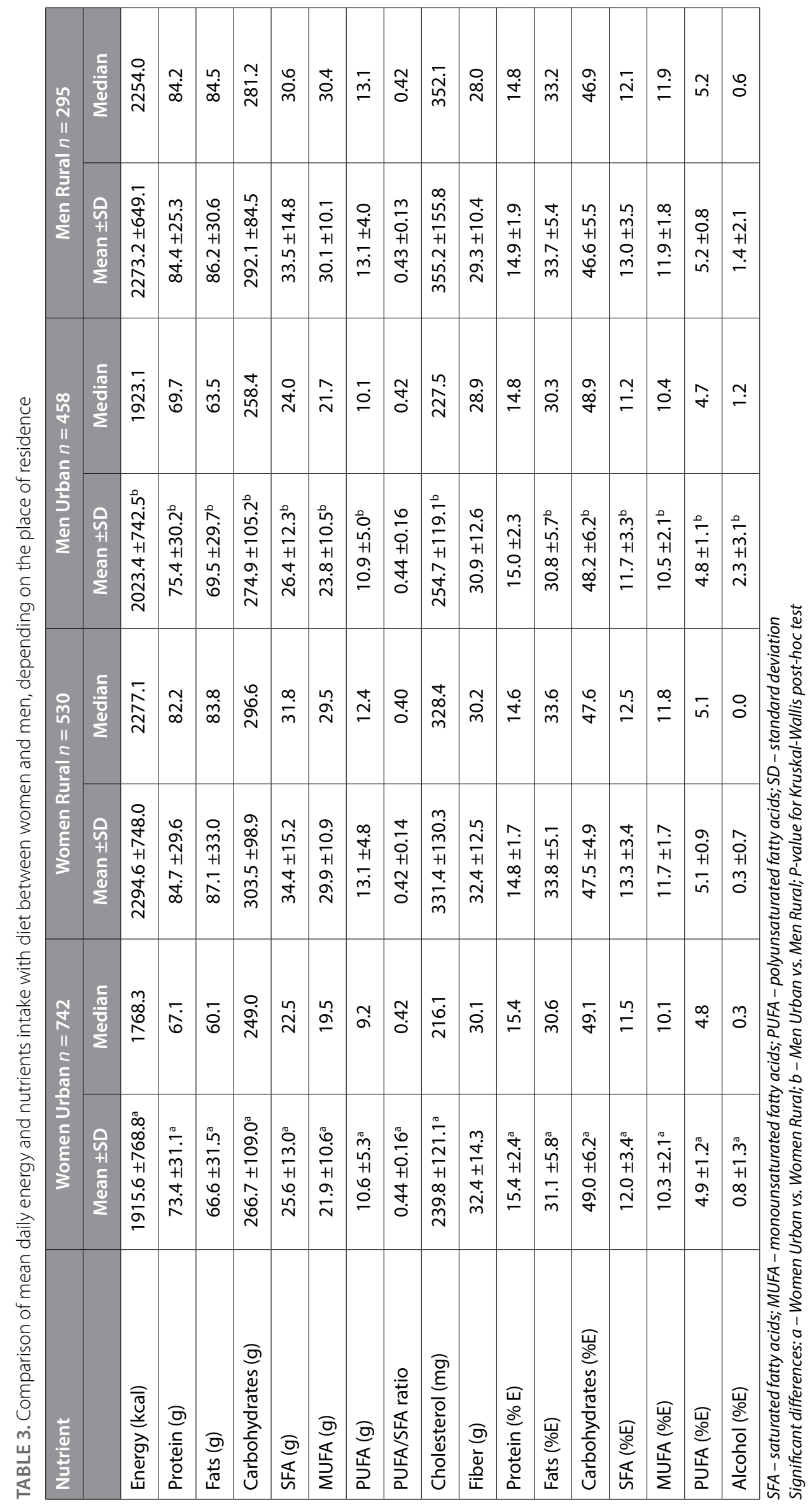


worth noted that insufficient consumption of these products favors an adequate supply of magnesium and B vitamins. However, it is indicated to choose food exhibiting a low glycemic index (GI), such as: whole-grain and rye bread, oat cereals or barley. Products with high GI and glycemic load (e.g., wheat rolls and bread, corn flakes, white rice) should be avoid, because it was observed that low GI and glycemic load were independently associated with a reduced risk of type 2 diabetes, coronary heart disease, breast cancer, gallbladder diseases, and all diseases combined [21].

Improper structure of fatty acids in the DFRs of the study group is typical for Polish population, as it was observed in other studies $[19,20]$. The improper proportion between fatty acids was defined by very low $\mathrm{P} / \mathrm{S}$ ratio. Excessive energy percentage from SFA in diets may be related to higher risk of cardiovascular disease (CVD). The current guidelines to reduce cardiovascular risk, prepared by the American College of Cardiology and the American Heart Association, states that adults who are required to reduce their LDL cholesterol level, should obtain $5 \%$ to $6 \%$ of their calories from SFA in the diet [9]. SFA in diet should be replaced by PUFA, what may contribute to decrease LDL cholesterol and the total to HDL cholesterol ratio [22]. Insufficient content of PUFA in the diets of study population indicates that intake of marine fish, canola, and linseed oil should be increased. On the other hand, it is not recommended to replace SFA by refined carbohydrates and added sugars, as it may decrease HDL cholesterol level, whereas it increases the levels of triglyceride and small LDL particles [22]. In the study of Jakobsen et al. [23], which involved 53,644 women and men, substituting SFA for low GI carbohydrates was related to lower risk of myocardial infarction, while substituting them for high GI foods had an inverse effects.

The development of CVD is different between people from rural and urban areas. As has been cited by Yusuf $e t$ al. [24], the coronary heart disease mortality rate, prevalence of hypertension, mean levels of serum cholesterol, and BMI were higher in urban than rural areas in China. On the other hand, the prevalence of diabetes in rural areas of India was lower than in urban. A strong exemplary evidence that nutritional habits also differ between rural and urban areas was also given by Yusuf et al. [25]. In China, the cereals products were a source of $57.4 \%$ of energy in diets among urban inhabitants, while in rural this figure was $71.7 \%$, whereas the animal products were a source of $15.2 \%$ and $6.2 \%$ of energy, respectively. Therefore, it is to justify to explore the eating habits of people residing in different areas, considering, that current increase in urbanization and mechanization leads to a decrease in physical activity in both urban and rural areas.

In our study, the inhabitants of urban areas compared to rural areas showed better nutritional patterns, what may have an impact on the prevention of obesi- ty and cardiovascular disease. Nevertheless, it cannot be ignored that there were about $70 \%$ of people with overweigh or obesity in urban area and $75 \%$ in rural. The diets of people residing urban areas contained lees energy, cholesterol, had lower percentage of energy from fats and SFA than the diets of those residing rural areas. Unfortunately, the percentage of energy from MUFA and PUFA were also lower. The ratio of energy from alcohol was lower in rural than urban. However, in the study conducted Kielce and Świętokrzyskie Voivodeship, Poland, such differences depending on place of residence had not been observed [20]. The similar observations as in the presented study were noted in the Cameroon Survey, where the diets of men and women residing in urban areas contained less calories and lower percentage of energy from fats, SFA, MUFA, and PUFA, whereas higher percentage of energy from carbohydrates than the diets of people from rural areas [26].

\section{CONCLUSIONS}

The study was aimed to compare energy and selected macronutrients (carbohydrates, dietary fiber, proteins, fats, fatty acids, cholesterol) intake with diet between men and women aged 35-70 years old from urban and rural areas of the Lower Silesia, who participated in the Polish arm of the PURE study. The diets that were closer to recommendations were observed among women and people residing in urban areas, compared to men and people residing in rural areas. However, the diets of participants in every groups require multiple amendments.

The study also identified the proportion of individuals who did not meet dietary recommendations. The improper contribution of energy from selected macronutrients was observed in the studied diets what was mainly caused by excessive percentage of energy from SFA and too low from PUFA. This caused a very low $\mathrm{P} / \mathrm{S}$ ratio. Almost $40 \%$ of the study group consumed too much of cholesterol, while about one-third did not consume enough amounts of dietary fiber. The dietary changes should be implemented in the study population what will be beneficial in prevention of non-communicable diseases.

\section{DISCLOSURE}

The main PURE study and its components are funded by the Population Health Research Institute, the Canadian Institutes of Health Research, Heart and Stroke Foundation of Ontario and through unrestricted grants from several pharmaceutical companies, Poland substudy: Polish Ministry of Science and Higher Education (grant no. 290/W-PURE/2008/0), Wroclaw Medical University.

Authors report no conflict of interest.

\section{References}

1. Kourlaba G, Panagiotakos D. Dietary quality indices and human health: A review. Maturitas 2009; 62: 1-8. 
2. Ferro-Luzzi A, James W, Kafatos A. The high-fat Greek diet: a recipe for all? Eur J Clin Nutr 2002; 56: 796-809.

3. Martin SS, Khokhar AA, May HT, et al. HDL cholesterol subclasses, myocardial infarction, and mortality in secondary prevention: the Lipoprotein Investigators Collaborative. Eur Heart ) 2015; 36: 22-30

4. Yokoyama Y, Nishimura K, Barnard ND, et al. Vegetarian diets and blood pressure a meta-analysis. JAMA Intern Med 2014; 174: 577-587.

5. Mahmood S, Levy D, Vasan R, et al. The Framingham Heart Study and the epidemiology of cardiovascular disease: a historical perspective. Lancet 2014; 383: 992-1008.

6. Lasker DA, Evans EM, Layman DK. Moderate carbohydrate, moderate protein weight loss diet reduces cardiovascular disease risk compared to high carbohydrate, low protein diet in obese adults: A randomized clinical trial. Nutr Metab 2008; 5: 30.

7. Riccardi G, Rivellese AA. Dietary treatment of the metabolic syndrome - the optimal diet. Br J Nutr 2000; 83: S143-S148.

8. American Dietetic Association, Dietitians of Canada. Positions of the American Dietetic Association and Dietitians of Canada: Vegetarian diets. J Am Diet Assoc 2003; 103: 748-765.

9. Eckel RH, Jakicic JM, Ard JD, et al. 2013 AHA/ACC Guideline on Lifestyle Management to Reduce Cardiovascular Risk: A Report of the American College of Cardiology/American Heart Association Task Force on Practice Guidelines. Circulation 2014; 129 (25 Suppl 2): S76-S99.

10. Piepoli MF, Hoes AW, Agewall S, et al. 2016 European Guidelines on cardiovascular disease prevention in clinical practice. Eur Heart J 2016; 37: 2315-2381.

11. Teo K, Chow CK, Vaz M, et al. The PURE Investigators-Writing Group. The Prospective Urban Rural Epidemiology (PURE) study: Examining the impact of societal influences on chronic noncommunicable diseases in low-, middle-, and high-income countries. Am Heart J 2009; 158: 1-7.e1.

12. Corsi DJ, Subramanian SV, Chow CK, et al. Prospective Urban Rural Epidemiology (PURE) study: Baseline characteristics of the household sample and comparative analyses with national data in 17 countries. Am Heart J 2013; 166: 636-646.e4.

13. Dehghan M, Ilow R, Zatonska K, et al. Development, reproducibility and validity of the food frequency questionnaire in the Poland arm of the Prospective Urban and Rural Epidemiological (PURE) study. J Hum Nutr Diet 2012; 25: 225-232.

14. US Department of Agriculture USDA, Agricultural Research Service 2011. USDA National Nutrient Database for Standard Reference, Release 24. Nutrient Data Laboratory Home Page. Available from: http://www.ars.usda.gov/ba/bhnrc/ndl (accessed 9 October 2011).

15. Kunachowicz H, Nadolna I, Przygoda B, et al. Tabele składu i wartości odżywczej żywności [Food Composition Tables]. Wydawnictwo Lekarskie PZWL, Warszawa 2005.

16. Merchant AT, Dehghan M. Food composition database development for between country comparison. Nutr J 2006; 5: 2 .

17. Jarosz M (ed.). Normy żywienia dla populacji polskiej - nowelizacja [Nutrition Standards for the Polish population amendment]. Instytut Żywności i Żywienia, Warszawa 2012.
18. Waśkiewicz A, Sygnowska E, Jasiński B, et al. Wartość energetyczna i odżywcza diety dorosłych mieszkańców Polski. Wyniki programu WOBASZ [The energy and nutritional value of the diets of adult Polish population. The results of the WOBASZ Study]. Kardiol Pol 2005; 63 (Suppl 4): S1-S7.

19. Ilow R, Regulska-Ilow B, Różańska D, et al. Assessment of dietary intake among 50-year-old inhabitants of Wroclaw in 2002-2007. Bromat Chem Toksykol 2012; 45: 1210-1218 [In Polish].

20. Ilow R, Regulska-Ilow B, Różańska D, et al. Assessment of dietary intake in a sample of Polish population - baseline assessment from the prospective cohort 'PONS' study. Ann Agric Environ Med 2011; 18: 229-234.

21. Barclay AW, Petocz P, McMillan-Price J, et al. Glycemic index, glycemic load, and chronic disease risk - a meta-analysis of observational studies. Am J Clin Nutr 2008; 87: 627-637.

22. Siri-Tarino PW, Sun Q, Hu FB, et al. Saturated fatty acids and risk of coronary heart disease: modulation by replacement nutrients. Curr Atheroscler Rep 2010; 12: 384-390.

23. Jakobsen MU, Dethlefsen C, Joensen AM, et al. Intake of carbohydrates compared with intake of saturated fatty acids and risk of myocardial infarction: importance of the glycemic index. Am J Clin Nutr 2010; 91: 1764-1768.

24. Yusuf S, Reddy S, Ôunpuu S, et al. Global burden of cardiovascular diseases: Part II: Variations in cardiovascular disease by specific ethnic groups and geographic regions and prevention strategies. Circulation 2001; 104: 2855-2864.

25. Yusuf S, Reddy S, Ônpuu S, et al. Global burden of cardiovascular diseases: Part I: General considerations, the epidemiologic transition, risk factors, and impact of urbanization. Circulation 2001; 104: 2746-2753.

26. Mennen LI, Mbanya JC, Cade J, et al. The habitual diet in rural and urban Cameroon. Eur J Clin Nutr 2000; 54: 150-154.

\section{AUTHORS' CONTRIBUTIONS}

$\mathrm{RI}, \mathrm{KZ}, \mathrm{AS}$ and WAZ prepared the research concept and design of the publication. DR, BRI, RI, MW, AM, KK and AS collected data. DR and $B R I$ analysed data. DR, BRI and $A B$ wrote the article. $K Z$ and $A S$ critically reviewed the publication. WAZ finally approved the publication. 